ISSN 2236-0859

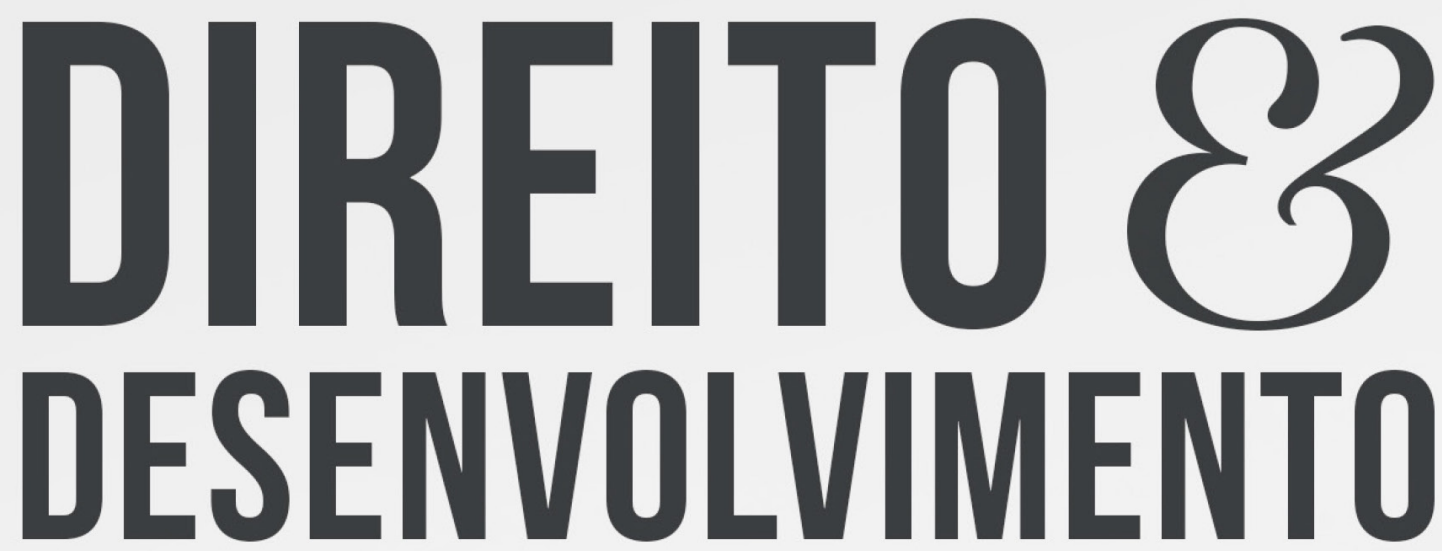

REVISTA DO PROGRAMA DE PÓS-GRADUACÃO EM DIREITO MESTRADO EM DIREITO E DESENVOLVIMENTO SUSTENTÁVEL

\title{
A BRECHA TECNOLÓGICA COMO UM DOS OBSTÁCULOS AO DESENVOLVIMENTO
}

ANDRÉ RICARDO FONSÊCA DA SILVA 


\title{
A BRECHA TECNOLÓGICA COMO UM DOS OBSTÁCULOS AO DESENVOLVIMENTO
}

\section{TECHNOLOGICAL BREAK AS ONE OF THE OBSTACLES TO DEVELOPMENT}

Recebido: 15/07/2020

Aprovado: 16/07/2020

André Ricardo Fonsêca da Silva'

\section{RESUMO:}

O presente artigo buscou examinar a brecha tecnológica como um dos obstáculos ao desenvolvimento. A abordagem foi feita com foco na análise da igualdade na distribuição de oportunidades de acesso às tecnologias da informação e da comunicação (TIC) no contexto dos indicadores utilizados para medir o acesso às TIC. A abordagem metodológica apontou-se como qualitativa, dedutiva com a técnica de revisão bibliográfica em material brasileiro e estrangeiro. Na pesquisa, constatou-se que a inclusão digital como objeto da redução das desigualdades sociais só se dá se as TIC forem apropriadas como instrumentos que propiciem aos usuários digitais uma melhoria real das suas vidas, transformando-os de indivíduos acríticos em cidadãos conscientes, reflexivos e críticos das informações colhidas nas TIC.

Palavras-chave: Inclusão Digital. Pobreza. Desenvolvimento.

\begin{abstract}
:
This article sought to examine the technological gap as one of the obstacles to development. The approach was made with a focus on analyzing equality in the distribution of opportunities for access to information and communication technologies (ICT) in the context of the indicators used to measure access to ICT. The methodological approach was pointed out as qualitative, deductive with the technique of bibliographic review in Brazilian and foreign material. In the research, it was found that digital inclusion as an object of reducing social inequalities only occurs if ICTs are appropriated as instruments that provide digital users with a real improvement in their lives, transforming them from uncritical individuals into conscious, reflective citizens and critics of information gathered from ICT.
\end{abstract}

Keywords: Digital inclusion. Poverty. Development.

\section{INTRODUÇÃO}

No contexto social da Era Informacional a qual estamos inseridos surgem várias perguntas, tais como: está havendo a igualdade na distribuição de oportunidades de acesso às tecnologias da informação e da comunicação (TIC)? 1 Doutor em Políticas Públicas e Formação Humana pela UERJ, Mestre em Ciências Jurídicas pela UFPB, Especialista em Direito Municipal pela UNIPÊ e Graduado em Direito pela UNIPÊ. Professor do Programa de Mestrado em Direito e Desenvolvimento do Centro Universitário de João Pessoa (UNIPE). E-mail: professor.andrefonseca@gmail.com 
Há obstáculos no acesso às TIC? A desigualdade social e econômica são barreiras para a diminuição da desigualdade de acesso às TIC? A brecha tecnológica é um retrato da exclusão social?

Desta feita, este artigo busca analisar a brecha tecnológica como um dos obstáculos ao desenvolvimento. Para tanto, foi desenvolvida uma pesquisa qualitativa, que não tem por foco a elaboração de dados estatísticos, apesar de alguns momentos serem analisados dados de instituições oficiais, por exemplo do IBGE. Além disso, foi utilizado o método dedutivo, partindo do tema geral brecha tecnológica, para chegar no tema específico que trata da brecha tecnológica ratificada pela pobreza, o que afeta o desenvolvimento de parcela dos cidadãos brasileiros. Concomitantemente foi utilizada a técnica de pesquisa de revisão bibliográfica, levantando informações em livros, periódicos, indicadores sociais governamentais e dados do Ministério das Comunicações, Ministério da Educação, do IBGE e da PNAD.

Assim, permeados pelos questionamentos realizados anteriormente, fizemos a seguinte divisão: a seção 2 apresenta uma reflexão da expressão brecha tecnológica - sua origem, sinônimos; a seção 3 destaca a pobreza e a exclusão digital e é subdividida nos tópicos - a pobreza como uma expressão da desigualdade e a exclusão digital e a desigualdade social; a seção 4 enfatiza o processo de não inclusão digital no Brasil e; finalmente, a seção 6 estão as considerações finais do trabalho.

\section{A EXPRESSÃO BRECHA TECNOLÓGICA}

Em meados dos anos 9o surgiu o termo digital divide que acabou sendo muito difundido por meio dos discursos do presidente e vice-presidente dos Estados Unidos, Bill Clinton e Al Gore, respectivamente. Ninguém sabe ao certo quem o utilizou pela primeira vez, mas inicialmente ele era usado para distinguir a postura de otimismo e pessimismo em relação às inovações tecnológicas da época (LEAL, 2010).

Com a difusão, este termo acabou tendo diversos sinônimos: democratização do acesso às TIC, acesso universal, acesso equitativo, infoinclusão, infoexclusão, apartheid digital, digital gap, brecha digital, brecha tecnológica, fratura digital, exclusão digital, inclusão digital entre outros (FERNANDES DE ALENCAR, 2008). Mais recentemente, este termo passou a ser empregado para definir a desigualdade existente entre os que possuem e os que não possuem acesso às novas tecnologias, em especial à Internet, e sobre as possibilidades de informação disponibilizadas na rede (LEAL, 2010).

Já os países hispano-americanos adotam o termo brecha tecnológica ou brecha digital e, de acordo com a ALADI (Asociación Latinoamericana de Integración), refere-se à linha que divide o grupo de pessoas que têm acesso às TIC do grupo que não possuem acesso. No Brasil é mais comum encontrarmos os termos inclusão digital e exclusão digital, ou infoinclusão para designá-los.

A inclusão digital pode ser conceituada, pois, como o processo de democratização do acesso às novas TIC e melhores condições de vida a todos os cidadãos, permitindo que estes se insiram na sociedade informacional. Já a exclusão digital seria o termo usado para resumir todo um contexto que impede a maioria das pessoas de participarem dos benefícios das novas TIC.

Destarte, o termo inclusão digital pode envolver diferentes áreas, tais como educação, comunicação, ciência da computação e ciência da informação. Além disso, a ação de inclusão digital pode ser presidida pelo governo ou pela sociedade civil, por exemplo organização não- 
governamental. Estes fatores já demonstram que o termo inclusão digital é um termo em constante evolução. (MEDEIROS NETO; MIRANDA, 2009)

Outros autores, como Rodrigues e Maculan (2012), preferem usar o termo fratura digital ("tradução" da expressão inglesa digital divide), para expressar, inicialmente, a desigualdade de acesso às TIC. Porém, atualmente, fratura digital deve ser usada para expressar não só o desafio da diminuição da lacuna de acesso às TIC como também a capacidade cognitiva dos indivíduos no acesso a estas tecnologias. Neste sentido, conforme Bruno (BRUNO et al., 2011) o termo fratura digital torna-se multidimensional por envolver as facetas de acesso e de capacidade.

Como no Brasil é comum utilizar as expressões inclusão digital e exclusão digital para tratar do acesso desigual às tecnologias de informação e comunicação, do acesso aos computadores e do acesso à Internet tomando como base ao que foi definido pela Organização para a Cooperação e Desenvolvimento Econômico (OCDE), então, no decorrer deste trabalho empregaremos este binômio, que inclusive é utilizado pelo governo federal para a elaboração de indicadores.

Discutir sobre inclusão e exclusão digital nos faz pensar se estes termos estão relacionados à exclusão social, ou seja, ser excluído digital é, também, ser excluído social?

O relatório "Redefinindo a Exclusão Digital" (Redefining the digital divide), publicado em novembro de 2013 pela EIU (Economist Intelligence Unit), traz informações relevantes, mostrando que apesar do aumento significativo na última década em relação ao acesso à Internet, ao aumento da largura de banda, à mobilidade etc, percebeu-se que as pessoas deixadas para trás estão ficando ainda mais para trás na sociedade atual (ANDREASSON, 2013). De acordo com o relatório:

- A renda e a acessibilidade são as principais contribuições para a exclusão digital atualmente $(63 \%)$, seguidos da falta de habilidades digitais para o uso das tecnologias digitais (56\%).

- Quem deve financiar a solução para a exclusão digital continua sendo o maior ponto de discórdia entre os líderes do governo e da indústria (30\%), seguido por divergências sobre a necessidade de reforçar as habilidades de TI (17\%) e o papel da concorrência e da regulamentação (15\%).

- Habilidades digitais - a habilidade de uma pessoa para acessar, adaptar e criar conhecimento usando as ferramentas digitais - foram citadas com "muito" ou "parcialmente importante" por 99\% dos participantes, enquanto $100 \%$ dos entrevistados acredita que as habilidades digitais se tornarão mais importantes para as pessoas e empresas ao longo dos próximos três anos.

- Parcerias, tais como o trabalho do setor privado com subsídios do setor público (49\%) ou parcerias formais Público-Privadas (41\%), são consideradas as melhores abordagens para chegar a soluções para a exclusão digital. Apenas $17 \%$ dos participantes acha que o setor privado sozinho é mais indicado para resolver o desafio da exclusão digital.

Ao visualizar este cenário é importante mapear os processos de inclusão e exclusão e, desta forma, elaborar estratégias que envolvam toda a sociedade, o poder público e o setor privado evitando um novo tipo de marginalização e, consequentemente, uma avalanche de pessoas excluídas socialmente. 


\section{A POBREZA E A EXCLUSÃO DIGITAL}

Para dialogarmos a pobreza com a exclusão digital, achamos melhor fazermos uma divisão, onde inicialmente retratamos a pobreza como uma expressão da desigualdade e, posteriormente, falaremos da exclusão digital (com suas várias denominações) e a desigualdade social.

\subsection{A pobreza como uma expressão da desigualdade}

O fenômeno da pobreza tem sido objeto de estudos há muito tempo, pois no desenvolvimento histórico das sociedades, sempre esteve imersa na convivência social do ser humano. Para entendermos melhor sobre a relação da pobreza com a exclusão digital, faremos, inicialmente, um estudo conceitual sobre pobreza.

A pobreza pode ser vista por várias abordagens:

1) a partir de diferentes fundamentos teórico metodológicos: positivistas (funcionalistas, estruturalistas) marxistas;

2) do ponto de vista do desenvolvimento histórico social e político da sociedade capitalista: do Estado liberal (prevalência do mercado) ao Estado social (direitos sociais); 3) do ponto de vista da definição dos indicadores, as medidas da pobreza podem ser monetárias, quando utilizam a renda como principal determinante da linha de pobreza e podem recorrer a indicadores multidimensionais, que incluem atributos não monetários para definir a pobreza, como o IDH, e o índice Gini. Esses indicadores multidimensionais incluem aspectos que afetam o bem-estar dos indivíduos e a não satisfação de suas necessidades básicas. Consideram como essencial para definir a condição de pobreza o acesso a alguns bens, de modo que sem esses os cidadãos não são capazes de usufruir uma vida minimamente digna. Incluem: água potável, rede de esgoto, coleta de lixo, acesso ao transporte coletivo, educação saúde e moradia. O caráter multidimensional da pobreza leva à necessidade indicadores que tenham uma correspondente abordagem multidimensional e que levem em consideração como indivíduo percebe sua situação social. (YAZBEK, 2012, p. 290-291)

No que se refere às possibilidades de se identificar a pobreza, há duas grandes vertentes: uma delas é descritiva e a outra é a política. A caracterização da pobreza, conforme a análise descritiva, consiste no reconhecimento de um estado de privação. Já na percepção política, identifica-se a pobreza como resultado de um processo de exclusão política. As duas análises podem ser complementares, de acordo com Sen (2010), sendo que a pobreza descritiva pode ser utilizada como diagnóstico.

Já outra maneira de se estudar a pobreza é seguirmos as grandes perspectivas filosófico políticas: estado liberal, estado neoliberal e marxismo. Para isto, iremos iniciar o estudo falando sobre o liberalismo.

Os ideais liberais se baseiam na liberdade de todos os homens em possuir propriedades privadas. Inclusive John Locke estabelece que é papel dos governos assegurar ao seu povo a garantia dos direitos de propriedade, caso contrário deveria ser substituído.

Para Locke, que foi o precursor do liberalismo político e defensor dos ideais burgueses, escreveu o livro Segundo Tratado sobre o Governo Civil (169o), onde descreveu a importância da razão humana para a superação do estado de natureza, e defendeu também como princípios essenciais em uma sociedade a existência de um governo civil que assegure a todos, indistintamente, os direitos naturais. Assim, Locke entendia que todo ser humano tem, 
naturalmente, o direito à vida, à felicidade, à liberdade, à independência e à propriedade. A igualdade encontra-se no interior da doutrina dos direitos naturais.

Entre o final do século XVIII e o início do século XX, cresce o liberalismo econômico, que teve como propósito garantir a predominância da burguesia sobre as demais classes, e também a busca daquela classe de se defender da atuação interventiva do Estado.

Nesse diapasão, cabe destacar Adam Smith (1723-1790) que ficou conhecido como pai do liberalismo econômico, e em 1776 publicou sua mais notável obra a Riqueza das Nações, que influenciou todo o pensamento econômico da época, sendo considerado o marco do surgimento da economia política como um novo ramo do conhecimento científico. Os seguidores de Adam Smith, conhecidos como "clássicos", entendiam que o princípio que regula a vida econômica é a livre concorrência a ausência do Estado como regulador da economia, o que ficou conhecido como "mão invisível". Smith, portanto, revolucionou a economia ao propor a ideia de que o mercado seria autoajustável e naturalmente eficiente por meio da interação dos indivíduos em um sistema de livre mercado.

Para Smith, a verdadeira riqueza das nações está no trabalho, o qual deve ser guiado pela livre iniciativa dos empreendedores. Desta forma, na ótica liberal, base da sociedade capitalista, o valor de um bem depende do trabalho empregado para sua obtenção (GASTALDI, 2009). Assim, a riqueza de qualquer nação está diretamente relacionada à quantidade e qualidade do trabalho de que essa nação possa dispor, atribuindo, pois, ao trabalho a noção de valor.

A sua visão otimista se aplica à produção das riquezas, mas ele não chega a sustentar que as riquezas são distribuídas entre os homens da maneira mais equitativa possível. É um liberal hostil à intervenção do Estado no domínio econômico, pois a julga não somente inútil, mas nefasta. Seu liberalismo, entretanto, nada tem de intransigente, e, em certos casos, a intervenção dos poderes públicos parece-lhe absolutamente justificada.

Sandroni (1999) destaca que a filosofia do liberalismo foi criticada por novas escolas do pensamento econômico desenvolvidas já na segunda metade do século XIX, pois seus princípios não mais se adequavam à nova realidade econômica. Nesse período, onde houve a expansão do capitalismo, surgiram também crises de superprodução, além de alta concentração de renda e de propriedade. Assim, o auto ajustamento da oferta e da procura não funcionou muito bem na prática, não proporcionando uma harmonia entre os interesses individuais e os coletivos em uma sociedade.

Desta forma, houve no liberalismo um acúmulo de riqueza que trouxe por consequência o poder econômico, porém este poder cresceu de tal forma que se transformou num abuso do poder econômico que fez com que a igualdade do liberalismo vira-se uma piada (NEVES, 2003).

Para Smith a existência da pobreza é percebida como um processo natural, pois é fruto das diferenças individuais. Ele pensa que todos, na sociedade liberal, podem ser proprietários, até mesmo os mais pobres, pois o que explica as diferenças sociais são o ócio e a tendência para a preguiça dos pobres.

No pensamento de Smith o progresso econômico propiciaria a eliminação da pobreza, seja diretamente pela geração de emprego e renda e indiretamente via elevação do padrão de vida dos trabalhadores e da produtividade do trabalho.

Neste contexto a importância da diminuição da exclusão digital, pois com a inclusão digital dos excluídos socialmente, poderia haver uma inclusão social e a oportunidade dos pobres saírem da pobreza. Entretanto, não é isso que estamos visualizando, pois a diminuição da exclusão digital não se dará apenas por meio do acesso às TIC, é necessário também a criação e desenvolvimento da competência informacional (como será demonstrado abaixo), que só se dará através da educação. 
Para o liberalismo clássico a igualdade de oportunidades é possível se houver a igual atribuição dos direitos fundamentais à vida, à liberdade e à propriedade. Assim, para que cada um alcance a posição apropriada à sua máxima capacidade, faz-se mister a igualdade de direitos (BOBBIO; MATTEUCCI; PASQUINO, 2000).

Entretanto, esta igualdade de direitos prescrita pela teoria liberal clássica não foi suficiente para que os socialmente desfavorecidos tivessem acesso às oportunidades a qual a burguesia tinha. Assim, na prática liberal o que aconteceu foi um favorecimento ao acúmulo de bens pela burguesia frente ao proletariado.

Desta forma, fazem-se necessários privilégios jurídicos e materiais, ou seja, distribuições desiguais, para que os não privilegiados economicamente sejam nivelados em oportunidades frente aos privilegiados. Daí a necessidade da diminuição da brecha digital, que marca socialmente a sociedade desigual a qual estamos inseridos e só aumenta o fosso social caso não seja minimizada a exclusão digital.

Já na percepção neoliberal há vários autores, como Schultz, Becker, Friedman e Hayek. Sendo este último o principal formulador do neoliberalismo, por isso será objeto principal das nossas análises.

Não tinha como Hayek negar a existência de pessoas em situações de miséria e também dos desempregados. Desta forma, no seu pensamento essas pessoas são consideradas como sendo perdedoras. Apesar de admitir que algumas dessas pessoas sejam perdedoras não apenas por falta de competência, mas porque tiveram azar nas suas vidas. Porém não deixam de serem perdedores. (LEHER, 2010)

Para Hayek (1987) é inegável que o Estado de Direito gera desigualdade, porém ela não é criada intencionalmente.

Na visão neoliberal, há uma continuidade da interpretação liberal de igualdade, ou seja, consiste na possibilidade de todos serem inseridos no mercado, uns como proprietários dos meios de produção, já outros apenas como vendedores da sua força de trabalho. Assim, apenas o acesso às TIC já satisfaz ao neoliberalismo, não é o foco do neoliberalismo a busca de políticas estruturantes (conforme será analisado mais a frente) para a mitigação da brecha digital por meio do aumento da competência informacional. O que fica demonstrado o individualismo neoliberal.

Para Hayek (1987) para os pobres apenas restam duas opções:

a) intervenções compensatórias emergenciais por parte do Estado;

b) ação solidária e filantrópica da sociedade civil e de empresas "socialmente" responsáveis.

Já na visão marxista, contrariando o pensamento neoliberal (que a desigualdade é interpretada como sendo necessária para o progresso), a desigualdade tem fundamento estrutural no processo de produção de riquezas da sociedade capitalista. A exploração entre os que detêm os meios de produção (capitalistas) e os que vendem suas capacidades produtivas (proletários) tende sempre a beneficiar a acumulação de capitais nas mãos dos primeiros.

O Estado não é um agente neutro e suporta a ideologia da classe capitalista (ideologia que camufla/esconde os artifícios políticos que tentam justificar/naturalizar a desigualdade).

As ideias liberais de direitos e justiça não são emancipatórias, mas alienantes:

a) enfatizam direitos individuais (p. ex. propriedade privada) em contraposição a natureza social - comunitária - das relações humanas;

b) promovem a ilusão igualitária (direitos e justiça), ao tempo que é marcada pela diferença de poder entre as classes. 
Na visão marxista, a exclusão digital é mais uma das expressões da questão social, ou seja, é consequência da relação dialética da sociedade capitalista, onde o burguês quer sempre lucrar mais em cima da mão de obra vendida dos proletariados que é vendida a preço baixo e só gera mais lucro ao burguês.

A exclusão digital serve para ratificar ainda mais a desigualdade social existente na sociedade capitalista.

Portanto, após fazermos uma relação das teorias clássicas da política em relação à exclusão digital, é importante entendermos que a pobreza não pode ser mais vista como uma chaga aberta que remete um atraso socioeconômico que envergonha um determinado país. Deve ser sim objeto de políticas públicas que quebrem o círculo perverso da pobreza (família pobre, educação incompleta, desemprego, pobreza).

As políticas públicas devem ser focadas na inserção do pobre, buscando combater o comodismo e a ociosidade provocados pelo assistencialismo, seguindo um pensamento de substituição do Welfare State para Workfare State. Inclusive a educação seguida de política de trabalho deve ser no sentido de gerar qualificação profissional, intermediação de emprego e crédito para gerar novos empreendedores, daí a importância da inclusão digital para poder propiciar melhoria de empregabilidade, o que nos remonta à igualdade.

Entendemos que o aumento de capacidades que gerará o aumento da possibilidade de recebimento ou até melhoria de renda, ou seja, os investimentos em políticas sociais voltadas para educação e saúde podem estar relacionados ao aumento da renda de populações envolvidas.

Neste sentido, Sen (2010) destaca que a melhoria dos serviços, tais com os educacionais não apenas melhoram a qualidade de vida, como também geram a maior possibilidade do indivíduo auferir renda, dando-se a possibilidade de sair da pobreza.

Entendemos, pois que a inclusão digital também pode ser um propiciador da melhoria das condições de vida dos indivíduos, possibilitando uma redução das desigualdades sociais. Porém, para que haja esta inclusão é necessário ter uma melhoria educacional do povo brasileiro, que permita que os indivíduos tenham capacidade para serem cidadãos ativos na sociedade informacional. Assim, é de suma importância ter um estudo sobre a relação da inclusão digital com a inclusão social, permeado pela busca da igualdade, o que será objeto do próximo tópico.

\subsection{A exclusão digital e a desigualdade social}

As TIC têm influenciado as relações sociais em todas as partes do mundo e têm sido determinantes para um novo modo de vida na sociedade. Neste sentido, podemos estar em vários lugares sem termos a necessidade de sair dos nossos quartos, podemos interagir com amigos através de meios de comunicação tão eficientes que dão a sensação de estarmos ao lado da outra pessoa.

E no contexto dessas relações nesta rede global, Internet, que surgem diversas discussões provenientes do surgimento de uma nova sociedade, a cibersociedade. A própria denominação dada a estas transformações advindas do desenvolvimento tecnológico tem provocado discussões entre os pesquisadores. Silveira (2001) utiliza a expressão Revolução Informacional, já Castells (1999) prefere chamar este período de Era da Informação.

Percebemos que da mesma forma como as máquinas a vapor marcaram as indústrias têxteis no século XIX, a informação e seus mecanismos de transmissão e armazenamento estão aumentando a capacidade de agir e se comunicar dos indivíduos. 
Entretanto, esta percepção não pode ser usada de forma a dizer que houve uma ruptura com a sociedade industrial ou até mesmo que provocou uma ruptura no modo de produção capitalista. Isto porque há uma continuidade do capitalismo, mas sob novas bases, ou seja, um modelo de desenvolvimento industrial que se funda na inovação tecnológica.

Assim, nesta era das TIC houve transformações em vários setores da sociedade, contudo a realidade social capitalista continua gerando dominação, exclusões e desigualdades. Por isso, a importância de entendermos a exclusão digital num contexto da sociedade capitalista marcada pelas expressões da questão social.

Ao estudarmos sobre exclusão digital percebemos uma ligação direta com as discussões sobre igualdade e desigualdade. Tendo em vista que a desigualdade social favorece a exclusão digital, e esta intensifica a desigualdade social, tanto que os pobres são, comumente, os excluídos também da sociedade em rede (ANDREASSON, 2013).

Há autores (ASSUMPÇÃO; MORI, 2006) que defendem que a inclusão digital é propiciadora da inclusão social, pois pode possibilitar o aumento da empregabilidade, melhores condições para o desenvolvimento de comunidades antes isoladas. Porém, apenas o acesso às TIC não foi suficiente para melhorar as condições de vida das classes mais pobres, pois só o acesso não propicia uma verdadeira inclusão digital que promova a inclusão social.

Temos que lembrar que a falta de acesso às informações disponibilizadas pelas TIC aumenta a lacuna ( $\mathrm{gap}$ ) entre os cidadãos que tiveram acesso à informação e aqueles que foram excluídos deste acesso. Desta forma, a exclusão digital afeta diretamente a inclusão social, ou seja, falar-se em inclusão digital é o mesmo que se falar em cidadania, em igualdade dos indivíduos.

Cabe, pois, retornarmos ao ponto da necessidade do desenvolvimento da capacidade cognitiva para que os indivíduos possam processar as informações de forma que sejam estimuladores da melhoria de vida dos indivíduos, sejam cidadão ativos e críticos na sociedade em rede. Tendo em vista que a necessidade do desenvolvimento da capacidade cognitiva é bastante esquecida nos programas de inclusão digital do governo.

O desenvolvimento da capacidade cognitiva do indivíduo é conhecido na literatura estrangeira como information literacy, que, geralmente, é traduzido como competência informacional.

Para Dudziak (2002) a competência informacional pode ser definida como sendo o domínio do universo informacional, de forma que possa incorporar habilidades, conhecimentos e valores relativos à busca, acesso, avaliação, organização e difusão da informação e do conhecimento.

Como lembra Pinheiro (2007) a inclusão digital não deve ser entendida apenas como acesso às TIC, à rede, aos jogos. O indivíduo não deve se restringir a somente localizar a informação, deve sim ser capaz de entender a informação, avaliá-la e usá-la, proporcionando o auto aprendizado.

Neste diapasão, percebe-se a importância da competência informacional para que o usuário das TIC tenha um papel ativo como produtor de conhecimentos e não apenas um papel passivo de receptor acrítico de informações.

Já Silva Filho (2003) ressalta que a inclusão digital envolve três pilares, que são as TIC, a renda e a educação. Isto porque mesmo que haja o acesso à renda, faz-se necessário o outro pilar educação, porque apenas o acesso à renda e às TIC se não souber utilizar e até mesmo acessar as tecnologias digitais não haverá uma boa funcionalidade da informação. 
Figura 1 - Inclusão Social

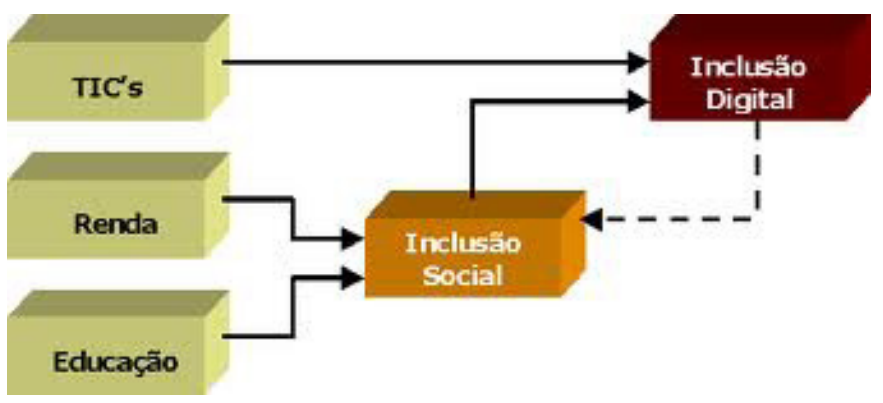

Fonte: SANTOS, RAFALSKI, 2014, p. 16

Portanto, apenas conceder acesso a baixo custo de computadores às pessoas não é inclusão digital, é necessário também ensiná-los a utilizar estas ferramentas digitais de forma eficaz, maximizando as informações acessadas e sendo um sujeito crítico ativo destas informações colhidas nas TIC.

Inclusive, em algumas campanhas eleitorais no Brasil, foi muito prometido pelos candidatos acesso a baixo custo de tablets, como se apenas isso pudesse incluir os excluídos digitais e que fosse impactar diretamente na diminuição da desigualdade da sociedade brasileira.

É preciso que as ações relacionadas à inclusão digital sejam menos teóricas, e sim mais práticas e eficazes à vida social dos indivíduos e das comunidades, pois o que é mais comum é se perceber que quanto mais pobre é uma determinada comunidade menos investimentos chegam até ela, inclusive os investimentos relacionados à inclusão digital, o que aumenta ainda mais os problemas sociais. (ANDREASSON, 2013; MITCHELL, 2002)

Neste contexto, defendemos que a desigualdade social favorece a exclusão digital e esta também estimula a desigualdade social, aumentando a lacuna (gap) social, ou seja, um ciclo que se retroalimenta.

Para melhor explicar a relação direta entre a desigualdade social e a exclusão digital, iremos elencar algumas tabelas que demonstram o processo de inclusão no mundo e depois do Brasil.

A tabela 1 e a figura 2 apresentam uma visão global da situação da internet no mundo com dados populacionais e de acesso à internet. Vale ressaltar que o gráfico obtido pela última coluna da tabela 1 sinaliza as porcentagens de usuários da internet. Percebe-se, na tabela 1, que há uma maior inclusão digital nas regiões mais ricas. Já em regiões mais pobres, como a África, observa-se que são regiões extremamente marcadas pelo não acesso às TIC, o que aumenta a desigualdade destas regiões em comparação com as regiões mais ricas, como a Europa.

Tabela 1 - Usuários de internet x população mundial

\begin{tabular}{|c|c|c|c|c|c|c|}
\hline \multicolumn{7}{|c|}{$\begin{array}{c}\text { WORLD INTERNET USAGE AND POPULATION STATISTICS } \\
\text { June } 30,2012\end{array}$} \\
\hline World Regions & $\begin{array}{l}\text { Populaticen } \\
\text { (2012 Est.) }\end{array}$ & \begin{tabular}{|c|} 
Intemer Ukenrs \\
Doc. 31, 2000
\end{tabular} & $\begin{array}{l}\text { Intemer Users } \\
\text { Latest Dats }\end{array}$ & $\begin{array}{l}\text { Pentration } \\
\text { (4) Population) }\end{array}$ & $\begin{array}{c}\text { Growth } \\
2050-2012 \\
\end{array}$ & $\begin{array}{l}\text { Users \& } \\
\text { of Table }\end{array}$ \\
\hline Africa & 1073,390525 & $4,5 \div 4,400$ & $167,375,676$ & $15.6 \%$ & $3,606.7 \%$ & $7.0 \mathrm{~N}$ \\
\hline Asla & $3 \subseteq 22,095 \mathrm{~s} \theta ?$ & $114,304,050$ & $1,076,6 \mathrm{al}, 059$ & $27.5 \%$ & $847.9 \%$ & $4.8 \%$ \\
\hline Eurape & $220,918,446$ & $106,096,050$ & $516,512,109$ & $60.2 \%$ & 293.25 & $21.5 \%$ \\
\hline Middle East & 223,606203 & $3,204,050$ & $90,000,455$ & $40.2 \%$ & $2619.9 \%$ & $3.7 \%$ \\
\hline North Americs & $340,290,154$ & $100,096,050$ & $273,725,413$ & $28.6 \%$ & 153.35 & $11.4 \%$ \\
\hline Latin America / Carlbbean & $593,696,630$ & $18,060,919$ & $254,915,745$ & $42.9 \%$ & $1,310.05$ & $0.6 \%$ \\
\hline Occania / Australla & $35,950 \leqslant 69$ & $7,620+400$ & $24,2 \mathrm{el,919}$ & $67.6 \%$ & $210.7 \%$ & $1.0 \%$ \\
\hline WORLD TOTAL & $7,017,045,922$ & $950,905,492$ & $2,405,510,976$ & $34.3 \%$ & $566.4 \mathrm{~s}$ & $100.0 *$ \\
\hline
\end{tabular}

Fonte: www.internetworldstats.com/stats.htm 
Figura 2 - Usuários da Internet no mundo - Distribuição pelas regiões - 2012

\section{Internet Users in the World} Distribution by World Regions - 2012 Q2

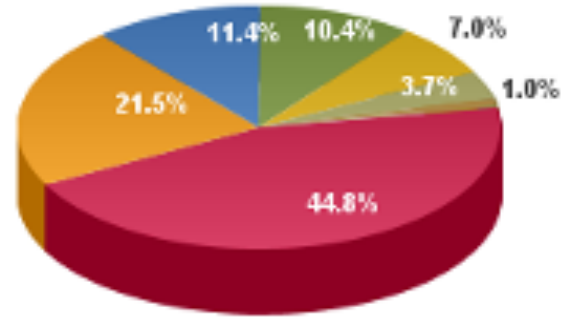

Asia 44.8\%

Europe $21.5 \%$

North America 11.4\%

Lat Am / Caribb $10.4 \mathrm{~W}$

Afriga $7.0 \%$

Middle East $3.7 \%$

Oceania / Australia 1.0\%

Fonte: www.internetworldstats.com/stats.htm

Tabela 2 - Domicílios particulares permanentes, conforme algumas características - Brasil - 2011-2012

\begin{tabular}{|c|c|c|c|c|}
\hline \multirow{3}{*}{ Abumas caracteristicas } & \multicolumn{4}{|c|}{ Domiclios particulsres permanentes } \\
\hline & \multicolumn{2}{|c|}{2011} & \multicolumn{2}{|c|}{2012} \\
\hline & Total & Percentual (\%) & Toted & Percentual (2) \\
\hline Iuminaxáo elétrica & 60879 & 99.3 & 62546 & 99.5 \\
\hline Teletione & ssces & 89,9 & 57327 & 91,2 \\
\hline Somonte movel colular & 30482 & 49,7 & 32284 & 51,4 \\
\hline Somente fixo convercional & 2123 & 3.5 & 1857 & 30 \\
\hline Codular e fixo convercionsl & 22481 & 36,7 & 23186 & 36,9 \\
\hline Fogao & 60447 & 98,6 & 62063 & 98,3 \\
\hline Fillo de dous & 32617 & 53.2 & 33364 & 53.1 \\
\hline Geladera & 58690 & 95,8 & 60744 & 96,7 \\
\hline Froozer & $100 \mathrm{nt}$ & 16,4 & 10469 & 16,3 \\
\hline Maquina de Laar noupa & 31250 & 51.0 & 34654 & 55.1 \\
\hline Radio & 51135 & 83,4 & 50821 & 80,9 \\
\hline Televisao & 59381 & 96,9 & 61092 & 97,2 \\
\hline DVD & 46298 & 75.5 & 47784 & 76,0 \\
\hline Mirocomputador & 26307 & 42,9 & 29137 & 46,4 \\
\hline Microcomputador conn acesso a lntomot & 22395 & 36,5 & 25325 & $\infty 0,3$ \\
\hline cerro & 25006 & 40.9 & 26663 & 42.4 \\
\hline Monocicleta & 11679 & 19,1 & 12583 & 20,0 \\
\hline
\end{tabular}

Fonte: IBGE, Diretório de Pesquisas, Coordenação do Trabalho e Rendimento, Pesquisa Nacional por Amostra de Domicílios 2011-2012.

Na tabela 2 verifica-se que quase metade $(46,4 \%)$ dos lares brasileiros possuem computadores. E apenas 40,3\% dos lares brasileiros têm acesso à internet, o que evoluiu ao se comparar os anos de 2011 e 2012.

A figura 3 mostra que aproximadamente 83 milhões de pessoas com idade superior a dez anos declararam ter acessado a internet nos três meses anteriores à pesquisa realizada pelo IBGE em 2012, o que significou um aumento de 6,8\% em relação ao ano anterior (IBGE, 2012) 
Figura 3 - Percentual das pessoas que utilizaram a Internet, no período de referência dos últimos três meses, na população de 10 anos ou mais de idade, segundo os grupos de idade - Brasil - 2011-2012

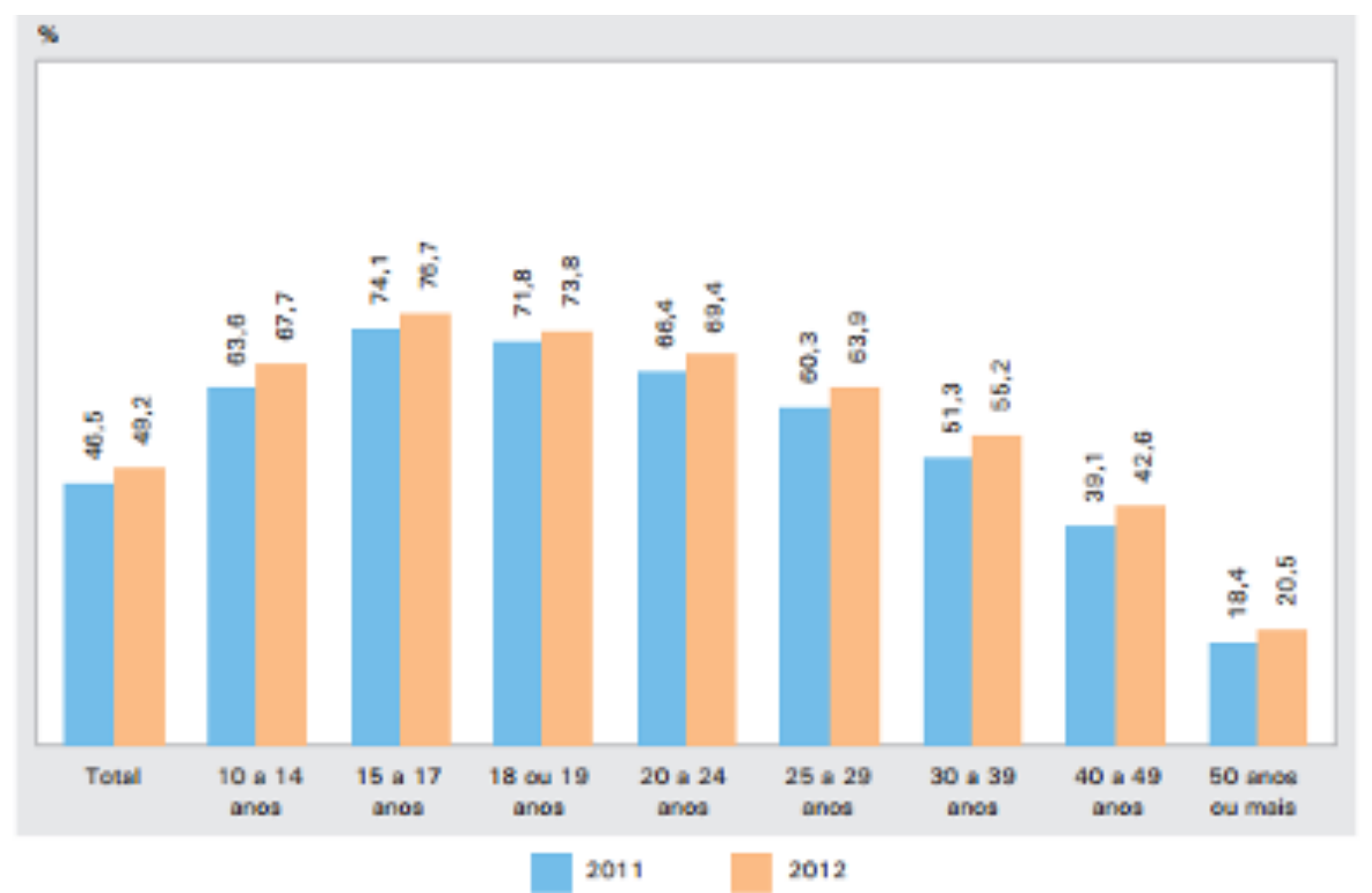

Fonte: IBGE, Diretório de Pesquisas, Coordenação do Trabalho e Rendimento, Pesquisa Nacional por Amostra de Domicílios 2011-2012.

Vale ressaltar que o método utilizado pelo IBGE considera inclusão digital apenas o acesso à internet nos três meses anteriores à pesquisa. Entretanto, discordamos deste método, porque para se analisar a inclusão digital pensamos ser necessário a mensuração da influência do uso das TIC para inclusão social, tais como melhoria da empregabilidade. Diferente disso, apenas teremos índices estatísticos com grandes limitações, pois não vão ao cerne do problema que é a qualidade do acesso, tanto por parte da perspectiva da conexão de acesso a rede quanto por parte da competência informacional do usuário da TIC.

Neste sentido, Assumpção e Mori (ASSUMPÇÃO; MORI, 2006) lembram que a inclusão digital só se tornaria fator preponderante para uma inclusão social se possibilitar aumento de empregabilidade, melhores condições para o desenvolvimento das comunidades, participação e autonomia crítica provocadora de mudanças de práticas políticas.

Na Tabela 3 se depreende que a inclusão digital no Brasil está relacionada ao nível de desenvolvimento econômico de cada estado brasileiro, pois os estados das regiões norte que são bastante marcados pela pobreza têm baixa inclusão digital. Diferentemente, dos estados das regiões sudeste e sul que já possuem maior índice de inclusão digital. 
Tabela 3 - Domicílios particulares permanentes urbanos, total e proporção dos domicílios, por acesso a alguns serviços e posse de alguns bens duráveis, segundo as Grandes Regiões, Unidades da Federação e Regiões

Metropolitanas - 2008

\begin{tabular}{|c|c|c|c|c|c|c|c|c|c|}
\hline \multirow{3}{*}{$\begin{array}{l}\text { Grandes Regióen, } \\
\text { Unidases de Foberaçio e } \\
\text { Regides Metropoleanas }\end{array}$} & \multicolumn{9}{|c|}{ Domicilios particulares permenentes urbanes } \\
\hline & \multirow{2}{*}{$\begin{array}{c}\text { Toes } \\
\text { (1 } 1000 \text { ds- } \\
\text { micilios) }\end{array}$} & \multicolumn{3}{|c|}{$\begin{array}{l}\text { Proporçio, por acesso a } \\
\text { algunt servipes (\$S) }\end{array}$} & \multicolumn{5}{|c|}{$\begin{array}{c}\text { Proporça, por posse de alguns } \\
\text { bens duratveis (S) }\end{array}$} \\
\hline & & $\begin{array}{l}\text { llam: } \\
\text { napdio } \\
\text { elótricas }\end{array}$ & $\begin{array}{l}\text { Telo: } \\
\text { fone } \\
\text { fiso }\end{array}$ & Imaenet & $\begin{array}{c}\text { Compu- } \\
\text { tadsor }\end{array}$ & $\begin{array}{l}\text { Gola. } \\
\text { doire }\end{array}$ & Frowar & $\begin{array}{l}\text { TV em } \\
\text { cores }\end{array}$ & $\begin{array}{l}\text { Máquí: } \\
\text { na de } \\
\text { lavar }\end{array}$ \\
\hline Brasil & 48905 & 99,8 & 50.6 & 27.5 & 35.4 & 95,2 & 15.6 & 96.8 & 48,4 \\
\hline Norte & 3125 & 99,7 & 288 & 13.2 & 20.9 & 91,5 & 14,4 & 95,5 & 31,1 \\
\hline Rondónia & 327 & 99,4 & 32,1 & 19,6 & 26,2 & 96,2 & 15.3 & 94,5 & 31,4 \\
\hline Acte & 152 & 99,9 & 27,8 & 20,0 & 25,9 & 95,3 & 11,0 & 95,6 & 22,1 \\
\hline Amazonas & 643 & 99.9 & 38.1 & 14.9 & 26.2 & 94,8 & 19.9 & 97,6 & 57,5 \\
\hline Roraima & os & 100,0 & 26.8 & 16.2 & 2200 & 95,5 & 10.2 & 96,8 & 47,8 \\
\hline Parb & 1462 & 9,7 & 24.5 & 10,1 & 17,4 & 88,1 & 12,3 & 94,8 & 21,5 \\
\hline Regitos Metropolitana de Beltem & 1441 & 99,7 & 24,4 & 10.2 & 17.5 & 88,1 & 123 & 94,8 & 21,7 \\
\hline Amapa & 161 & 100,0 & 25.2 & 2.1 & 16.6 & 91,6 & 248 & 98.9 & 34,9 \\
\hline Tocantins & 202 & $\mathbf{m . 1}$ & 203 & 15.0 & 20.4 & 22,7 & at & 20,1 & 16.7 \\
\hline Sudoste & 23439 & 22.2 & 62,8 & 20,4 & 42,0 & 27,2 & 15.6 & 97,7 & Sa, \\
\hline Minas Gerais & 52801 & 99.9 & 51,3 & 26.7 & 35,6 & 95,7 & 2.7 & 96,8 & $\mathbf{3 6 , 4}$ \\
\hline Regibso Metropolitans de Belo Horizonte & 5216 & 99.9 & 51,4 & 26,9 & 35,8 & 95,7 & 98 & 96,8 & $\mathbf{3 6 , 6}$ \\
\hline Eapirito Santo & 873 & 99.9 & 50,7 & 31,6 & 38,6 & 97,2 & 23,1 & 97,1 & 39,7 \\
\hline Fío de Janairo & 5076 & 92.9 & 65,3 & 34,1 & 41,6 & 90,5 & 21,2 & 98,2 & 6,3 \\
\hline Regibso Metropelitana do Fio de Janeiro & 5668 & 99.9 & 65,3 & 34,1 & 41,7 & 98,5 & 21,2 & 98,3 & 63,3 \\
\hline Sáo Paulo & 12208 & 99.9 & 67,6 & 36.2 & 45,3 & 96,6 & 15.3 & 98,0 & 64,2 \\
\hline Regiba Metropelitana de Sás Paulo & 12013 & 209 & 67,8 & $x, 4$ & 45,5 & 9.6 & 15.5 & 96,0 & 64,4 \\
\hline sul & 7523 & 99.8 & 55,5 & 23,1 & 43,2 & 97,9 & 26,4 & 97,0 & 64,0 \\
\hline Pasand & 2892 & 99.8 & 58,3 & 30,8 & 44,0 & 97,8 & 18,1 & 96,3 & 59,6 \\
\hline Regias Metropelitana de Curitiba & 2874 & 998 & 58.5 & $\$ 4,0$ & 44,2 & 97,7 & 18.1 & 96.3 & 59,7 \\
\hline Sants Catarina & 1636 & 100.0 & 68.0 & 23.6 & 48.0 & 9.9 & 36.5 & 97.8 & 67.9 \\
\hline Pio Grande do Sul & 2205 & 92.8 & 58,4 & 20,3 & 35,8 & 97,5 & 28.9 & 97,1 & 67,2 \\
\hline Regibo Metropelitans de Porto Alegre & 2495 & 92.7 & 50,7 & 23.5 & 39.9 & 97.5 & 28.7 & 37,2 & 673 \\
\hline Centro-Oeste & 3713 & $\boldsymbol{m a s}$ & 448 & 26,4 & 30,3 & 96.5 & 16.7 & 95,6 & 37,5 \\
\hline Mato Grosso do Sul & 627 & $\$ 0.9$ & 382 & 222 & 30,3 & 96.8 & 16.6 & 94,6 & 33,0 \\
\hline Mato Grosso & 732 & 89.7 & 36.4 & 26,4 & 31,3 & 96,4 & 188 & 93.0 & 34,4 \\
\hline Goibs & 1649 & 90,9 & 42.0 & 19.5 & 27,7 & 96,7 & 12,9 & 95,8 & 29,7 \\
\hline Districe Federal & 705 & 100,0 & 67.2 & 47,3 & 56,1 & $\$ 8,4$ & 23,3 & 98,6 & 63,1 \\
\hline
\end{tabular}

Fonte: IBGE, Pesquisa Nacional por Amostra de Domicílios 2008.

Pinheiro (2007) destaca que há dois tipos de políticas sociais: as compensatórias e as estruturais. As compensatórias geram efeito imediato, porém superficiais. Já as políticas estruturais são as que visam uma geração permanente de renda, porque tem por fulcro gerar independência e auto sustentabilidade. Neste contexto a inclusão digital deve ser tratada como uma política estrutural, sendo focada na construção de uma real política de informação, onde o indivíduo possa ter acesso às informações e tenha capacidade informacional para interpretar e dialogar com estas informações. 
Neste sentido, faz-se necessário que haja uma política de inclusão digital consolidada e não uma política descontínua, uma política com ações integradas e não ações isoladas, uma política que ultrapasse os limites de meros investimentos em infraestrutura e sim pense na capacidade cognitiva crítica do usuário. Além disso, que haja uma política interministerial, pois a competência informacional dar-se-á por meio de uma evolução educacional da sociedade brasileira na era informacional.

Por último, é interessante falarmos sobre os indicadores de inclusão digital. Na obra Mapa da exclusão digital (NERI, 2012) podemos observar, com base no censo do IBGE, vários indicadores para traçar o perfil dos usuários digitais, por exemplo:

a) Gênero, onde se percebeu que as mulheres possuíam menos acesso;

b) Escolaridade, os indivíduos com nível superior incompleto são os principais incluídos digitais domésticos;

c) Unidades da Federação, os estados mais pobres têm um menor índice de incluídos digitais domésticos;

d) Raça, a população branca é mais incluída.

Percebe-se, pois uma maior preocupação com o acesso às TIC e não com a qualidade de acesso por falta de competência funcional do indivíduo.

Mattos e Chagas (2008) ressaltam que a literatura referente a análises das políticas públicas sobre a inclusão digital tendem a dizer que os indicadores de inclusão digital deveriam ser focados na análise de cinco aspectos principais:

a) inserção no mercado de trabalho e geração de renda;

b) melhoria nas relações entre cidadãos e poderes públicos;

c) melhoria e facilitação das tarefas cotidianas dos indivíduos;

d) o incremento de valores culturais e sociais, gerando um aprimoramento da cidadania;

e) difusão do conhecimento tecnológico.

Os indicadores de inclusão digital, ao invés de darem ênfase apenas no acesso do indivíduo às TIC (o que interessa muito mais ao mercado), deveriam se preocupar também com a mensuração, por exemplo, da inclusão do usuário digital no mercado de trabalho por ter adquirido conhecimentos na cibersociedade. Além disso, deveriam se preocupar também com a mensuração da participação ativa das pessoas que tiveram acesso digital.

Desta forma, indicadores de inclusão digital tradicionais, tais como número de pessoas conectadas à internet e número de computadores conectados à internet, não abrangem a real amplitude e complexidade da inclusão digital. Faz-se mister passar os limites desta análise puramente quantitativa para uma análise mais qualitativa que envolva também a medição de outros aspectos, por exemplo a capacidade cognitiva do usuário digital. Só neste sentido que se poderá falar em igualdade e impacto real dos indicadores na vida dos indivíduos (principalmente daqueles que já são desiguais socialmente).

\section{INCLUSÃO DIGITAL NO BRASIL}

Antes iniciar a discussão sobre a inclusão digital no Brasil, é importante salientar que a Meta 4 dos Objetivos de Desenvolvimento Sustentável da ONU é: "Assegurar a educação inclusiva e equitativa e de qualidade, e promover oportunidades de aprendizagem ao longo da vida para todas e todos". Para tanto, as Nações Unidas buscam estabelecer parcerias para o desenvolvimento. Por isso, organizações internacionais como o Banco Mundial, a Organização das Nações Unidas para a Educação, a Ciência e a Cultura (Unesco), a União Internacional de 
Telecomunicações (UIT) e inclusive a ONU definiram indicadores que pudessem tornar possível a geração de dados estatísticos sobre o acesso, uso e apropriação das TIC por indivíduos e organizações, e com isso possibilitar informações sobre a inclusão/exclusão digital no mundo.

É interessante que um indicador seja relevante, tenha confiabilidade na coleta dos dados e cobertura apropriada ao objetivo, além de ser replicável, atualizado periodicamente e ter a possibilidade de ser desagregado em níveis geográficos e/ou comparado no tempo (JANNUZZI, 2002). Logo, a formulação de indicadores é primordial para definir ações que permitam à universalização do acesso e do uso das TIC.

Neste sentido, o Comitê Gestor da Internet no Brasil (CGI.br), que foi criado em 1995, tem como missão acompanhar a evolução da Internet nos domicílios, nas empresas e nas escolas, além de produzir e disseminar indicadores e dados estatísticos sobre as TIC. Através do Centro de Estudos sobre as Tecnologias da Informação e da Comunicação (Cetic.br), um dos departamentos do Núcleo de Informação e Coordenação do Ponto BR (NIC.br), são elaborados relatórios, utilizando os dados estatísticos produzidos, para alimentar o governo com informações confiáveis e com isso, possibilitar a criação de políticas públicas bem como estimular a produção de trabalhos acadêmicos e científicos.

Um dos relatórios gerados pela pesquisa realizada pelo CGI.br é denominado TIC Domicílios que tem como objetivo medir a disponibilidade e o uso das TIC no Brasil por meio dos seguintes módulos temáticos (CGI.BR, 2013):

- perfil domiciliar;

- acesso às tecnologias de informação e comunicação no domicílio;

- uso de computadores, local e frequência de uso;

- uso da Internet;

- governo eletrônico;

- comércio eletrônico;

- habilidades com o computador e a Internet;

- uso de telefone celular;

- intenção de aquisição de equipamentos e serviços TIC.

A pesquisa desenvolvida segue padrões metodológicos com a preocupação de permitir comparabilidade internacional nos seus principais indicadores definidos por instituições como a União Internacional de Telecomunicações (UIT). Estão alinhadas também com os referenciais metodológicos propostos no manual da Conferência das Nações Unidas sobre Comércio e Desenvolvimento (UNCTAD), elaborado pela parceria entre a OCDE, o Instituto de Estatísticas da Comissão Europeia (Eurostat) e a aliança formada por diversas organizações internacionais denominada Partnership on Measuring ICT for Development. Além disso, o CGI.br utiliza os dados do Censo Demográfico Brasileiro de 2010 do IBGE, permitindo com isto a representatividade do universo de domicílios e da população brasileira com idade igual ou superior a 10 anos (Figura 5). 
Figura 5 - Dados utilizados na Pesquisa TIC Domicílios

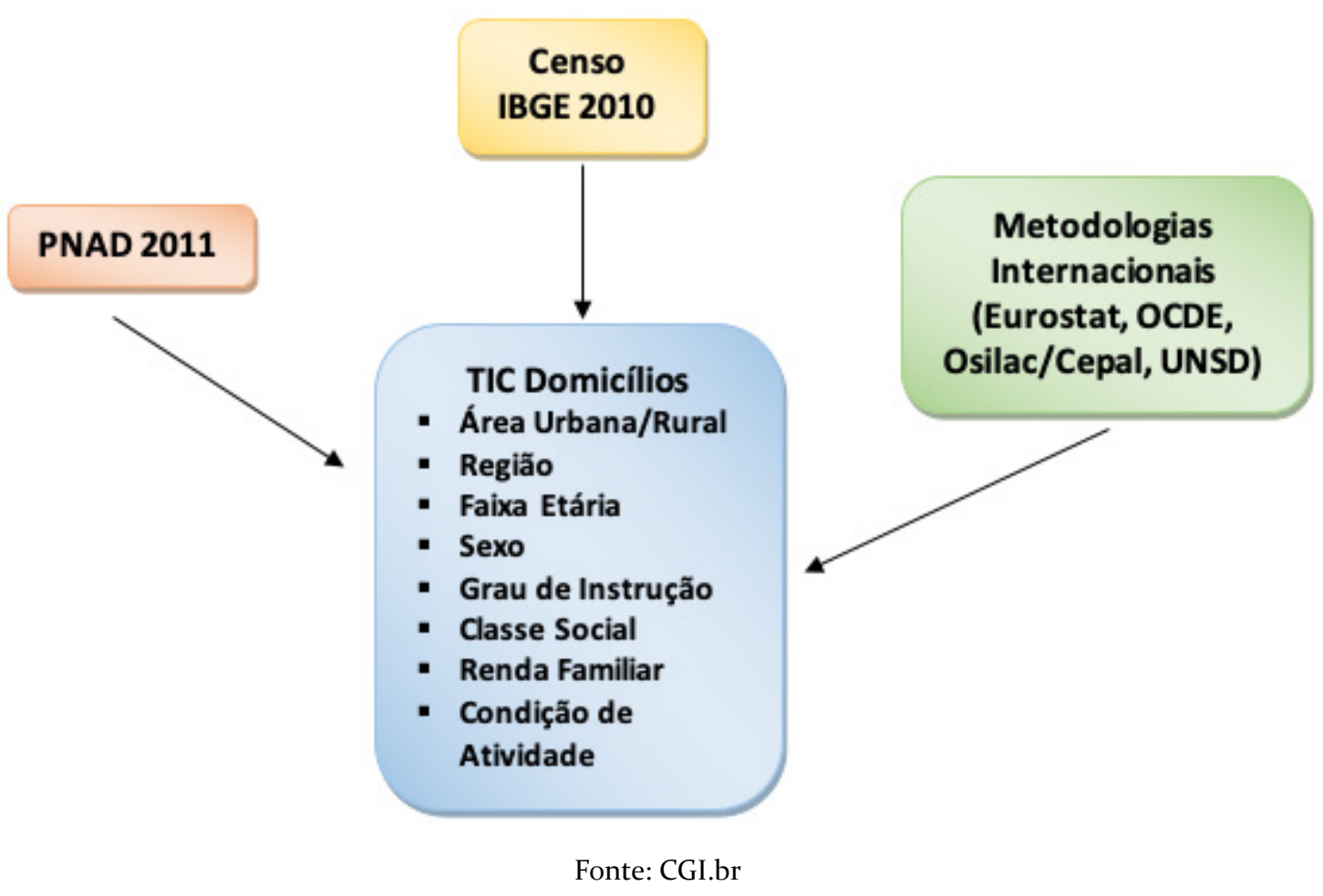

Em comparação com a última pesquisa realizada, observou-se um aumento na utilização da Internet. Em 2008, 53\% de brasileiros com idade igual ou superior a 10 anos utilizavam a Internet e em 2012 esse número chegou a 69\%, ou seja, atingimos a marca de 80,9 milhões de brasileiros nessa mesma faixa etária - um aumento de $19 \%$ em quatro anos. Os avanços alcançados nos últimos anos, contudo, não foram suficientes para solucionar disparidades relacionadas à condição socioeconômica e entre as diferentes regiões brasileiras.

De acordo com a pesquisa, quanto mais alta a faixa de renda e a classe social, maior a presença de computadores (foram considerados, na pesquisa, desktop e computadores portáteis - laptops, notebooks, netbooks e tablets. Não foram incluídos smartphones).

Outra diferença visualizada foi em relação às áreas urbanas e rurais e entre as regiões geográficas. Percebe-se que ainda existe uma grande disparidade entre as áreas com acesso à Internet: áreas urbanas (44\%) e rurais (10\%). Igualmente, o acesso à Internet nas diferentes regiões geográficas é também muito significativo: a região Sudeste possui a maior proporção de domicílios com acesso à Internet (48\%), seguido pelo Sul (47\%) e Centro-Oeste (39\%), enquanto Nordeste e Norte apresentam proporções muito inferiores: $27 \%$ e $21 \%$, respectivamente (CGI. $\mathrm{BR}, 2013)$. 
Figura 6 - Quantidade de pessoas que não acessa a Internet (por estado)

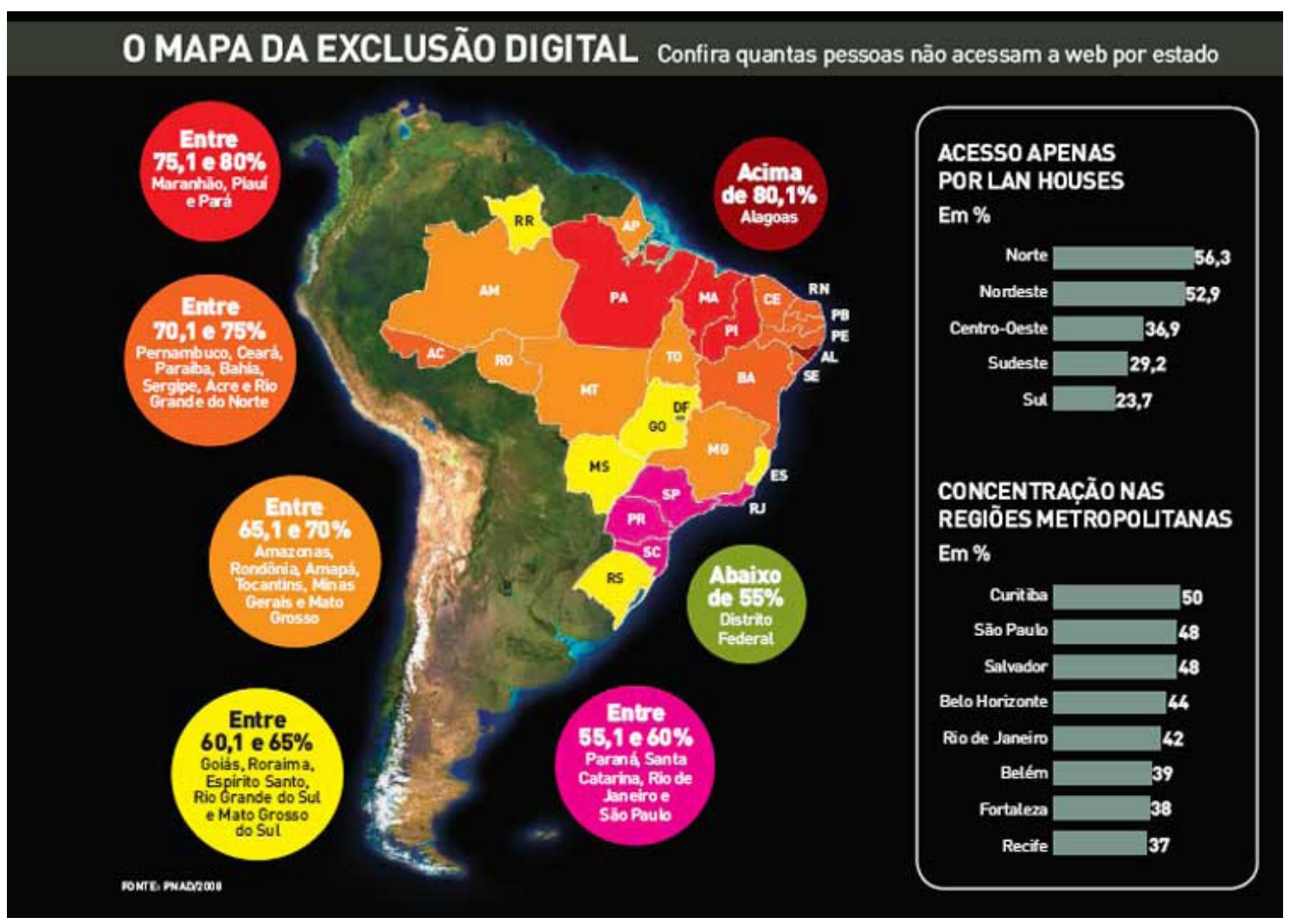

Fonte: PNAD (IBGE, 2014)

Entre as classes sociais também se observa uma grande desigualdade: $97 \%$ dos domicílios brasileiros de classe A e $78 \%$ de classe B possuem acesso à Internet, apenas 36\% dos domicílios da classe $\mathrm{C}$ e $6 \%$ da classe $\mathrm{D}$ e $\mathrm{E}$ estão conectados à rede. Como dito na seção anterior, esta pesquisa revela como a exclusão social pode afetar a exclusão digital.

A renda familiar baixa é uma das variáveis que melhor explica os motivos para a inexistência de computador nos domicílios. Conforme a pesquisa realizada, aqueles com renda acima de cinco salários mínimos citaram como motivo para a ausência de computador a falta de necessidade ou interesse. Já os que possuem renda inferior a três salários mínimos citaram como motivo o alto custo tanto dos equipamentos como dos provedores de Internet.

Num país com desigualdades econômicas e sociais, o alto custo dos equipamentos e dos serviços de conexão à Internet continua sendo um obstáculo ao acesso à rede, limitando a abrangência das ações de inclusão digital. Ainda assim, a quantidade de usuários e a frequência de uso da Internet vêm aumentando de maneira significante no Brasil, principalmente por conta da utilização da Internet em dispositivos móveis.

O Brasil ocupa o $60^{\circ}$ lugar no ranking, dos 155 países avaliados, sobre o desenvolvimento mundial das TIC. Para conhecer a posição brasileira no cenário mundial, a UIT (União Internacional das Telecomunicações) criou um índice, denominado IDI - ICT Development Index que é composto de onze indicadores agrupados em três categorias: habilidades (proficiência), acesso e uso das TIC - cada uma delas com composições próprias e diferentes pesos na formação do índice.

Todavia, o Brasil encontra-se bem abaixo de outros países dentre aqueles com os maiores PIB do mundo. Enquanto a França (5ํㅡㄹ maior PIB) está em 18o no ranking IDI, o Reino 
Unido (6º maior PIB) está em nono e a Rússia (8o maior PIB) está em 38ํ․ Na comparação com os índices alcançados pelas distintas regiões do mundo, o Brasil aparece muito próximo ao da Comunidade dos Estados Independentes (CEI) e abaixo da média das Américas e da Europa (Figura 7)

Figura 7 - Domicílio com acesso à Internet Brasil X Regiões do mundo (2005 - 2012)

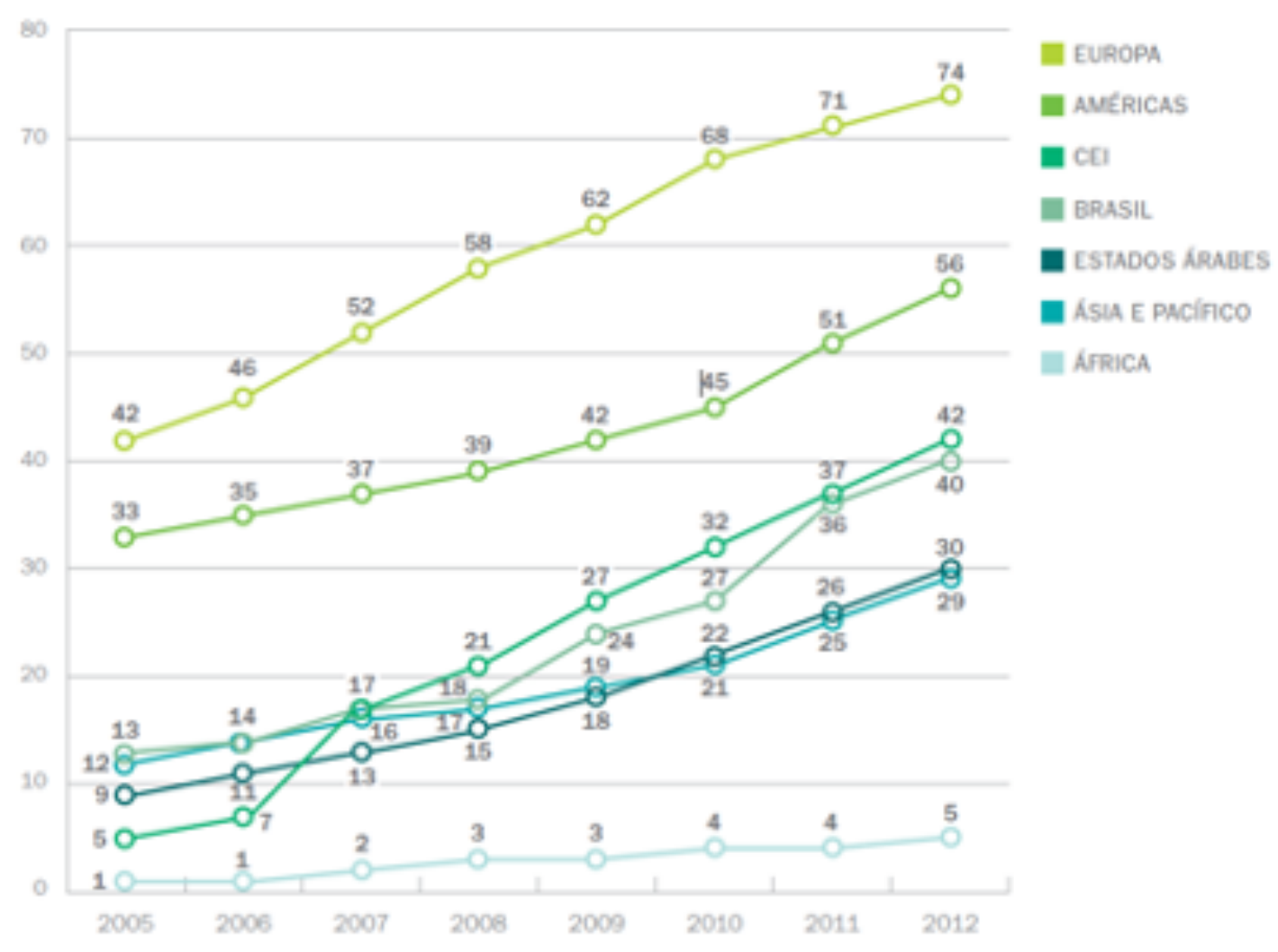

(Fonte sobre o IDI: ITU - Measuring The Information Society 2012 - Executive summary.

Fonte sobre o PIB: The World Bank: GDP (current US\$) - World Bank national accounts data and OECD National Accounts data files. Dados do PIB referentes a 2012.)

Mesmo em comparação com países da América do Sul, dados obtidos pela UIT, a proporção de domicílios brasileiros com computador (46\%) é inferior à verificada em países do Cone Sul, como Uruguai (64\%), Argentina (56\%) e Chile (54\%). O mesmo ocorre em relação a quantidade de usuários da internet, o Brasil possui a mesma proporção encontrada na Colômbia (49\%) aparece abaixo do Chile (61\%), da Argentina (56\%) e do Uruguai (55\%).

Isso nos mostra que o Brasil precisa avaliar a situação e elaborar políticas públicas que o coloquem melhor no cenário mundial e consequentemente, realizar uma melhor política de inclusão digital (social).

\section{CONSIDERAÇÕES FINAIS}

Entendemos, pois, que a inclusão digital é apenas uma das etapas da inclusão social, mas não que ela seja a razão única propiciadora para a verdadeira inclusão social, precisa haver em conjunto outras políticas públicas estruturais que propiciem e foquem a igualdade. 
Para isto nada melhor do que indicadores de inclusão digital eficientes que mensurem não apenas os acessos às TIC, mas também a competência informacional do usuário digital e, principalmente, possam demonstrar qual o impacto real da inclusão digital para a melhoria de vida dos indivíduos incluídos.

Os resultados encontrados em nossa pesquisa revelam que as políticas públicas voltadas à inclusão digital e ao acesso à Internet nos domicílios brasileiros ainda estão longe do ideal. Igualmente as políticas de fomento do acesso às tecnologias de informação e comunicação nos domicílios brasileiros e o uso das TIC pelos cidadãos não têm sido suficientes para diminuir as diferenças socioeconômicas entre as regiões urbanas e rurais e entre as diferentes classes sociais.

Assim, a inclusão social por meio da inclusão digital, ou seja, inclusão digital como objeto da redução das desigualdades sociais só se dá se as TIC forem apropriadas como instrumentos que propiciem aos usuários digitais uma melhoria real das suas vidas, transformando-os de indivíduos acríticos em cidadãos conscientes, reflexivos e críticos das informações colhidas nas TIC. Só dessa forma, acreditamos que o acesso às TIC pode contribuir para mitigação das desigualdades sociais do Brasil, impactando, inclusive, a pobreza que tão amarga a nossa sociedade.

Os indicadores de inclusão digital, ao invés de darem ênfase apenas no acesso do indivíduo às TIC (o que interessa muito mais ao mercado), deveriam se preocupar também com a mensuração, por exemplo, da inclusão do usuário digital no mercado de trabalho por ter adquirido conhecimentos na cibersociedade. Além disso, deveriam se preocupar também com a mensuração da participação ativa das pessoas que tiveram acesso digital.

Desta forma, indicadores de inclusão digital tradicionais, tais como número de pessoas conectadas à internet e número de computadores conectados à internet, não abrangem a real amplitude e complexidade da inclusão digital.

\section{REFERÊNCIAS}

ANDREASSON, K. Redefining the digital divide. [s.l.] The Economist Intelligence Unit Limited, nov. 2013.

ASSUMPÇÃO, R.; MORI, C. Inclusão digital: discursos, práticas e um longo caminho a percorrer. Disponível em: http://www.inclusaodigital.gov.br/noticia/inclusaodigitaldiscursos-praticas-e-um-longo-caminho-a-percorrer. 2006. Acesso em: 15 abr. 2020

BOBBIO, N.; MATTEUCCI, N.; PASQUINO, G. Dicionário de Política. 5. ed. Brasília, DF: $\mathrm{UnB}, 2000$.

BRUNO, G. et al. A critical analysis of current indexes for digital divide measurement. The information society, v. 27, n. 1, p. 16-28, 2011.

CASTELLS, M. A sociedade em rede: economia, sociedade e cultura. São Paulo: Paz e Terra, 1999.

CGI.BR, C. G. DA I. NO B. Pesquisa sobre o uso das tecnologias de informação e comunicação no Brasil: TIC Domicílios e Empresas 2012. São Paulo: [s.n.]. 
DUDZIAK, E. A. Information literacy: uma revolução silenciosa, diferentes recepções para a competência em informação. Anais do Congresso Brasileiro de Biblioteconomia e Ciência da Informação. Anais... In: FEBAB. Fortaleza, CE: 2002

FERNANDES DE ALENCAR, A. A infoinclusão e as estatísticas para a América Latina. In: Contribuciones para la pedagogía. [s.1.] CLACSO, 2008.

GASTALDI, J. P. Elementos de Economia Política. 19. ed. [s.l.] Saraiva, 2009.

HAYEK, F. A. VON. O caminho da servidão. Rio de Janeiro: Instituto Liberal, 1987.

IBGE. Indicadores socioeconômicos e demográficos - período 2011 e 2012. Disponível em: ftp://ftp.ibge.gov.br/Trabalho_e_Rendimento/Pesquisa_Nacional_por_Amostra_de_ Domicilios_anual/2012/Sintese_Indicadores/comentarios2012.pdf. Acesso em: 10 abr. 2020

IBGE. PNAD Contínua. Disponível em: ftp://ftp.ibge.gov.br/Trabalho_e_Rendimento/ Pesquisa_Nacional_por_Amostra_de_Domicilios_continua/Comentarios/pnadc_2013_04_ trimestre_comentarios.pdf. Acesso em: 10 abr. 2020

JANNUZZI, P. DE M. Indicadores Sociais no Brasil. Revista Brasileira de Administração Pública, v. 36, n. 1, p. 51-72, 2002.

LEAL, R. DE C. S. Usos e Apropriações dos "sem tela" na rede: um estudo comparativo sobre as condições de acesso dos jovens à Internet no Brasil e na Itália. Rio de Janeiro: Pontifícia Universidade Católica (PUC-RJ), 2010.

LEHER, R. Crise do capital e questão social. Estudos do Trabalho. Revista da RET, n. Ano III, número 6, 2010.

MATTOS, F. A. M. DE; CHAGAS, G. J. DO N. Desafios para inclusão digital no Brasil. Perspectivas em Ciência da Informação, v. 13, n. 1, p. 67-94, jan. 2008.

MEDEIROS NETO, B.; MIRANDA, A. Aferindo a inclusão informacional dos usuários de telecentros e laboratórios de informática de escolas públicas em programas de inclusão digital brasileiros. Informação \& Sociedade: Estudos, v. 19, n. 3, p. 109-122, set./dez 2009.

NEVES, R. S. O Estado Regulador. Revista de direito constitucional e internacional, n. 11, 2003.

PINHEIRO, M. M. K. Observatório da inclusão digital: descrição e avaliação dos indicadores adotados nos programas governamentais de infoinclusãoEncontro Nacional de Pesquisa em Ciência da Informação. Anais... In: VIII ENANCIB. Salvador: 2007

RODRIGUES, A. V.; MACULAN, A. M. D. Indicadores de inclusão digital. Rio de Janeiro: [s.n.], 2012.

SANDRONI, P. Novíssimo Dicionário de Economia. 19. ed. São Paulo: Saraiva, 1999. 
SANTOS, Washington. Romão dos; RAFALSKI, Jadson. Oficina de inclusão digital para a construção social: estudo de caso no CEET Vasco Coutinho - Espírito Santo, Revista Brasileira de Informática na Educação, Vol. 22, N. 3, 2014.

SEN, A. Desenvolvimento como Liberdade. São Paulo: Companhia das Letras, 2010.

SILVA FILHO, A. M. DA. Os três pilares da inclusão digital. Revista Espaço Acadêmico, v. 3, n. n. 24, Maio 2003.

SILVEIRA, S. A. DA. Exclusão digital: a miséria na era da informação. São Paulo: Fundação Perseu Abramo, 2001.

YAZBEK, M. C. Pobreza no Brasil contemporâneo e formas de seu enfrentamento. Serviço Social. 2012. n. 110, p. 288-322. 